Original article

\title{
Evaluation of quality and efficacy of an ethnomedicinal plant Ageratum conyzoides L. in the management of pediculosis
}

\author{
Sunita Shailajan*, Priyanka Wadke, Harshvardhan Joshi, Bhavesh Tiwari \\ Herbal Research Lab, Ramnarain Ruia College, Mumbai 400019, India
}

\section{A R T I C L E I N F O}

\section{Article history:}

Received 13 September 2013

Accepted 23 October 2013

Available online 27 December 2013

\section{Keywords:}

Ageratum conyzoides L.

Leaves

Bioassay

Eugenol

Pediculosis

\begin{abstract}
A B S T R A C T
Background: Infestation with the head louse, Pediculus humanus capitis, is one of the most common parasitic infestations of human worldwide. Traditionally, the main treatment for control of head lice is chemical control that includes wide variety of neurotoxic synthetic insecticides. The main difficulty posed in controlling the head louse infestation is increasing lice resistance to synthetic pediculicidal drugs. Plant-based drugs; especially essential oil components and standardized extracts have been suggested as an alternative source of materials for insect control. Ageratum conyzoides L. (Asteraceae) has been reported to possess antifungal and insecticidal properties. In the present research work, an attempt has been made to evaluate in vitro pediculicidal activity of $A$. conyzoides.

Methods: A filter paper diffusion bioassay was carried out in order to determine the pediculicidal activity of different extracts of $A$. conyzoides.

Results: The study elucidates the active plant part and suitable extract responsible for the therapeutic efficacy of this plant in the management of pediculosis.

Conclusion: Findings of the present study indicate the potential of $A$. conyzoides extract to be included in the formulations as a pediculicidal agent.

Copyright @ 2013, InPharm Association, Published by Reed Elsevier India Pvt. Ltd. All rights reserved.
\end{abstract}

\section{Introduction}

Pediculosis is a head infestation caused by the hematophagous lice Pediculus humanus capitis De Geer (Phthiraptera: Pediculidae), an obligate ectoparasite. ${ }^{1}$ Head lice infestation causes skin irritation, pruritus, urticaria, eczema, conjunctivitis, restlessness and sleep loss, as well as occasional secondary bacterial infection from scratching like impetigo and pyoderma. ${ }^{2-4}$ Traditionally, the main treatment to control head lice is chemicals which include a wide variety of neurotoxic synthetic insecticides such as DDT, lindane, malathion, carbaryl, permethrin and $\delta$-phenothrin. ${ }^{3}$ Besides the side effects, repeated use of these insecticides has often resulted in the development of resistance and may lead to multiple treatments including overdoses which raise serious human health concerns. ${ }^{4}$

Other most common strategies currently available include formulations of pesticides, combinations of herbs and use of lice combs. However, there is a dearth of efficacious and safe anti-lice formulations for use, especially for children. ${ }^{5}$ Different medicinal plants are often used against head lice in folk medicine in many

\footnotetext{
* Corresponding author. Tel.: +91 022 24154390; fax: +91 02224142480.

E-mail addresses: sunitashailajan@gmail.com, sunitashailajan@yahoo.co.in (S. Shailajan).
}

countries of the world. Researchers have focused and reported the pediculicidal potential of plant extracts or essential oils or secondary metabolites produced by them. ${ }^{1,2,6,7}$

Ageratum conyzoides L. (Asteraceae) is an aromatic, annual herb, native to tropical America and naturalised as a weed throughout India. It is a weed, commonly called Billygoat-weed, Goatweed etc., and generally found in cultivated fields and other ecosystems such as pastures, grasslands, wastelands and even forest areas. ${ }^{8}$ The plant is scientifically reported to possess anti-oxidant, ${ }^{8}$ wound healing, analgesic, anti-inflammatory, ${ }^{9}$ anti-malarial, ${ }^{10}$ anti-cancer, ${ }^{11}$ anti-hyperglycaemic, ${ }^{12}$ anti-ulcerogenic, ${ }^{13}$ anti-microbial and insecticidal $^{14}$ properties. Flavonoids (eupalestin, kaempferol, sinensetin, quercetin etc), triterpenes and sterols ( $\beta$-sitosterol, stigmasterol, brassicasterol etc), alkaloids (echinaline, lycopsamine etc), mono and sesquiterpenes (linalool, limonene, eugenol etc) and amino acids are reported as the phytochemical constituents from this plant. ${ }^{15}$ Amongst these phytochemical constituents, eugenol (Fig. 1) has been scientifically reported to be useful for the eradication of head lice infestation. ${ }^{2}$ The ethnomedicinal claim by the local tribes in India uncovered that $A$. conyzoides is a potential source for controlling pediculosis. In the present research work, a filter paper diffusion bioassay was performed in order to determine the pediculicidal activity of $A$. conyzoides. The traditional claim of 


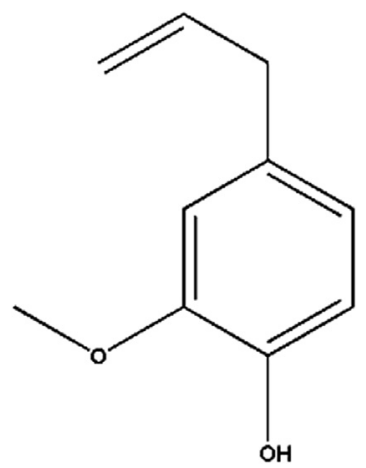

Fig. 1. Structure of eugenol.

A. conyzoides in the management of pediculosis and presence of a pediculicidal agent eugenol were considered as the main criteria for the selection of this plant.

Initially, in a preliminary study different extracts from whole plant of $A$. conyzoides ( $\mathrm{n}$-hexane, chloroform, ethyl acetate, acetone, ethanol and hydro-alcohol) were screened for their pediculicidal activity in vitro. In this experiment, the hydroalcoholic extract was found more effective. Further, hydroalcoholic extract from different plant parts of $A$. conyzoides were screened for their pediculicidal activity wherein the leaves were found more effective.

Finally, different samples of $A$. conyzoides leaves (hydroalcoholic extracts) were evaluated for their eugenol content using validated HPTLC method and the sample with maximum content was finally evaluated for its pediculicidal effect. The results were also compared with permethrin and Mediker (a well known oil based formulation available in the market for the management of head lice infestation). The study elucidates the active part and suitable extract responsible for the therapeutic effect of this plant in the management of pediculosis.

\section{Materials and methods}

\subsection{Collection, drying and storage}

Leaves of $A$. conyzoides were collected from different geographical regions of Maharashtra (Ambernath, Bhiwandi, Kalyan, Matunga, Murud, Vashi) and a representative sample was authenticated by Department of Botany (Voucher no. of Auth-HRL/ $11 / 11 / A C)$. The materials were washed and shade dried for three days followed by oven drying at $45{ }^{\circ} \mathrm{C}$ for four days. The dried materials were powdered separately, sieved (BSS mesh no. 85) and stored in airtight containers. Alpermy lotion (1\% permethrin, Densa Pharmaceuticals Pvt. Ltd., lot no. AL-045), Mediker (Marico Ltd., lot no. UA-009) and coconut oil (Marico Ltd., lot no. PR-018) was purchased from local market of Mumbai.

\subsection{Reference standard and reagents}

Eugenol (purity $\geq 99 \%$ ) was procured from Sigma-Aldrich Chemical Company (Steinheim, Germany). Organic solvents and chemicals of analytical grade were procured from Merck specialities Pvt. Ltd., India.

\subsection{Instrumental conditions}

The HPTLC system comprised of CAMAG TLC Scanner II supported by CATS 3 software equipped with CAMAG Linomat 4 sample spotter (spotting volume: $10 \mu \mathrm{L}$ ) and CAMAG Reprostar 3 system for photodocumentation. Chromatographic separation was achieved on TLC plates (E. Merck, pre-coated with silica gel $60 \mathrm{~F}_{254}$ on aluminium sheet support). All measurements were performed at $22 \pm 1{ }^{\circ} \mathrm{C}$.

\subsection{Quality evaluation of the plant sample}

Quality of the plant sample was evaluated for the parameters like ash content, extractive value, foreign matter and loss on drying as per the standard methods. ${ }^{16}$ Content of some major phytochemicals (fats and waxes, terpenoids and phenolics, alkaloids, quarternary alkaloids and $\mathrm{N}$-oxides) was determined as per the method reported by Harborne. ${ }^{17}$ Phytochemical fingerprint of the plant sample was developed using chloroform:methanol as a mobile phase $(9.8: 0.2, \mathrm{v} / \mathrm{v})$ on TLC plates. Methanolic sulphuric acid (10\%) was used as derivatizing agent.

\subsection{Preparation of hydroalcoholic extract of A. conyzoides leaves}

Hydroalcoholic extract of $A$. conyzoides leaves (HEACL) was prepared by extracting powdered sample $(1 \mathrm{~g})$ with $80 \%$ ethanol $(10 \mathrm{~mL}$, $\mathrm{w} / \mathrm{v}$ ). The mixture was vortex mixed for 1 min and kept standing overnight followed by filtration through Whatmann filter paper no. 1 (E. Merck, Mumbai, India). The filtrate was concentrated using rotary vacuum evaporator and the residue obtained was considered as HEACL.

\subsection{Estimation of eugenol content from different samples of HEACL}

An HPTLC method comprising of n-hexane:ethyl acetate (6:4, v/ v) was used as a mobile phase for separation of eugenol from the complex plant-based matrix of HEACL. Detection of eugenol was carried out by derivatizing the plate with $10 \%$ anisaldehyde sulphuric acid followed by visualization at $550 \mathrm{~nm}$. Different samples of HEACL were subjected for the estimation of eugenol content. Presence of eugenol in the samples analysed was putatively confirmed by comparing the $R_{f}$ and colour of the corresponding band with that of standard eugenol. The method was validated as per the ICH guidelines wherein the regression equation obtained from seven calibrant samples was used for determination of eugenol content.

\subsection{Evaluation of safety and efficacy of HEACL}

\subsubsection{Sample preparation for the safety and efficacy study}

HEACL $(5 \%, 10 \%, 15 \%$ and $20 \%)$ was prepared in coconut oil (total volume $1 \mathrm{~mL}$ ) and evaluated for its safety and efficacy profile.

\subsubsection{Safety evaluation of HEACL}

Safety of HEACL (20\% in coconut oil) was determined on rabbit skin by carrying out skin irritation study as per the method reported. ${ }^{18-21}$ The study was approved by the Institutional Animal Ethics Committee (CPCSEA/315).

\subsubsection{Evaluation of pediculicidal activity}

2.7.3.1. Collection of head lice. Head lice were collected from a population of children between the ages of 3 and 12 (from Mumbai, India), with the approval of their guardians. Lice were collected by raking a metal louse comb through sections of children's scalp and carefully removing lice from the metal teeth. After collection the lice were pooled and held on human hair strands. ${ }^{5}$ The subjects had not been treated with any pediculicide solution for at least the preceding month. ${ }^{22}$ As per the methods reported, head louse used in this study were protected from sunlight and heat and the in vitro test was started within $1 \mathrm{~h}$ after the collection of head lice. ${ }^{1,5}$

2.7.3.2. Bioassay. Filter paper diffusion method ${ }^{5,6,23}$ was employed in this bioassay. One millilitre of the test sample was distributed evenly 
over a filter paper ( $9 \mathrm{~cm}$ diameter) held in the lower half of glass petri dish ( $9 \mathrm{~cm}$ diameter). After $10 \mathrm{~min}, 10$ lice were placed carefully on the filter paper impregnated with the test sample with the help of ' 0 ' fine hair brush. The petri dish was covered with lid during the test and placed in an incubator $\left(37 \pm 2{ }^{\circ} \mathrm{C}\right.$ and $70 \pm 1 \%$ humidity). Observations of dead lice (\% mortality) were recorded at the time interval of 10, 20, 30,45 and 60 min post introduction of lice on the filter paper impregnated with the test sample. Different concentrations of HEACL (5\%, $10 \%, 15 \%$ and $20 \%)$ were tested for their pediculicidal activity. The results of the analysis were compared with permethrin (positive control), coconut oil (negative control) and Mediker.

\subsection{Statistical analysis}

Lethal dose $\left(\mathrm{LD}_{50}\right)$ and their associated confidence intervals were estimated from mortality data obtained at different time intervals using probit analysis. ${ }^{4}$ All differences were considered statistically significant if $P \leq 0.05$. Microsoft Excel-2007 was used for statistical analysis.

\section{Results and discussion}

A. conyzoides is an annual herb with a long history of traditional medicinal uses in the tropical and subtropical regions of the world. ${ }^{15}$ Leaves of this plant (Fig. 2) are opposite, pubescent with long petioles and include glandular trichomes. Aqueous extract from the leaves or whole plant of $A$. conyzoides have been used to treat colic, colds and fevers, diarrhoea, rheumatism, spasms, or as a tonic and as an insect repellent. The insecticidal property is the most important biological activity of this species. ${ }^{14,24}$ Thus, in this research work an attempt has been made to develop some quality control tools and evaluate the pediculicidal activity of $A$. conyzoides leaves.

\subsection{Quality control parameters for A. conyzoides leaves}

Results obtained for proximate analysis of $A$. conyzoides leaf powder are depicted in Table 1 . As these values are not part of any pharmacopoeia, the possible limits have been suggested. The fibre content of plant was $62.80 \pm 0.05 \%$. The plant material was rich in quaternary alkaloids and $\mathrm{N}$-oxides ( $17.60 \pm 0.02 \%$ ) while other phytochemicals in the plant sample were found in this order; terpenoids and phenolics $(4.20 \pm 0.09 \%)>$ fats and waxes $(2.20 \pm 0.02 \%)>$ alkaloids $(1.01 \pm 0.03 \%)$. The HPTLC fingerprint of the plant sample (before derivatization at $366 \mathrm{~nm}$ and after derivatization at $366 \mathrm{~nm}$ and $550 \mathrm{~nm}$ ) was developed and represented in Fig. 3. Different coloured

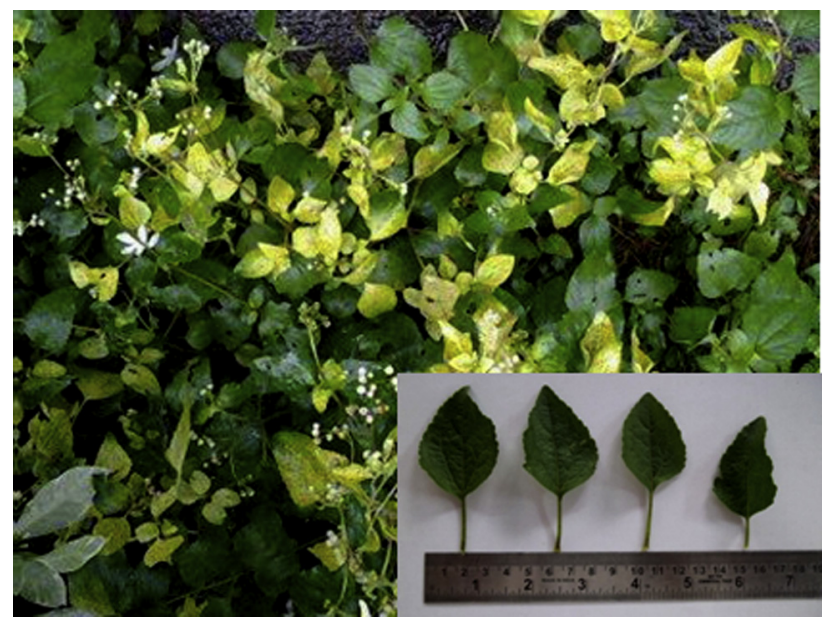

Fig. 2. Habit of Ageratum conyzoides (inset-leaves). bands were observed in the fingerprint. These quality control values obtained along with HPTLC fingerprint can be used as a reference to check the quality of the plant powder during its bulk collection.

\subsection{Estimation of eugenol content from HEACL}

Leaves of $A$. conyzoides are rich in essential oil content compared to other plant parts. ${ }^{24}$ Leaves of this plant are also reported to possess eugenol (a natural pediculicidal agent ${ }^{2}$ ). So far, there is no report on evaluation of eugenol content from the HEACL using any chromatographic method. Thus, in the present research work an HPTLC method has been developed and validated to estimate the eugenol content from HEACL.

Extraction of leaves using $80 \%$ ethanol gave a brownish green coloured residue (HEACL, yield: 22.45\%). During HPTLC experiment, separation of eugenol was achieved from the HEACL on TLC plates using n-hexane:ethyl acetate (6:4, v/v) as a mobile phase (Fig. 3). A characteristic band of eugenol was obtained at $R_{f}=0.54$ in the matrix of HEACL and its identity was putatively confirmed by overlaying the densitometric chromatograms and comparing the colour with that of the standard eugenol. The representative HPTLC plate photo of eugenol and HEACL is represented in Fig. 4.

The method was validated as per ICH guidelines and was found to be simple, rapid, specific, precise, sensitive and rugged during the validation experiment (Table 2). The method was applied to evaluate the impact of regional variation on the content of eugenol in A. conyzoides leaves collected from different provinces of India. Using the regression equation, the exact content of eugenol in the samples was determined. Significant variation in the eugenol content was observed in different samples analyzed using the validated HPTLC method (Table 3). Samples collected from various regions of Maharashtra showed the eugenol content in the range of $0.58-3.10 \mathrm{mg} / \mathrm{g}$. A. conyzoides leaves from Kalyan showed comparatively higher eugenol content $(3.10 \pm 0.04 \mathrm{mg} / \mathrm{g})$ than the samples collected from other regions. The eugenol content in the other samples was in this order: Matunga $>$ Vashi $>$ Bhiwandi $>$ Ambernath $>$ Murud.

Findings of the present work clearly suggest that there is a definite impact of geographical and environmental factors on the marker content of medicinal plants and the results were also in compliance with the other published reports. ${ }^{25}$ On the basis of the concentration of eugenol, hydroalcoholic extract of leaves collected from Kalyan were used for further safety and efficacy testing.

\subsection{Safety and pediculicidal activity of HEACL}

Topical application of HEACL on rabbit skin did not show any adverse effects and dermal irritation which was well supported by the values of Primary Irritation Index (average value was found to be 0 as there was no erythema or oedema caused). Results of safety study revealed that HEACL had adequate safety margin to be used on human skin.

There are several well documented studies which report the use of plant extracts as medicinal products against a broad spectrum of

Table 1

Results for the proximate analysis of A. conyzoides leaves.

\begin{tabular}{lcc}
\hline Parameters & $\begin{array}{l}\text { Results }(\% \text { mean } \pm \text { SD, } \\
n=3)\end{array}$ & $\begin{array}{l}\text { Suggested limits } \\
(\%)\end{array}$ \\
\hline Foreign organic matter & $0.52 \pm 0.05$ & $0.37-0.67$ \\
Ethanol soluble extractive & $18.69 \pm 1.19$ & $15.19-22.17$ \\
Water soluble extractive & $18.33 \pm 1.20$ & $14.73-22.23$ \\
Total ash & $12.06 \pm 0.36$ & $11.98-13.14$ \\
Acid insoluble ash & $0.96 \pm 0.06$ & $0.78-1.14$ \\
Water soluble ash & $4.12 \pm 0.10$ & $3.82-4.42$ \\
Loss on drying & $10.76 \pm 0.17$ & $10.25-11.27$ \\
\hline
\end{tabular}




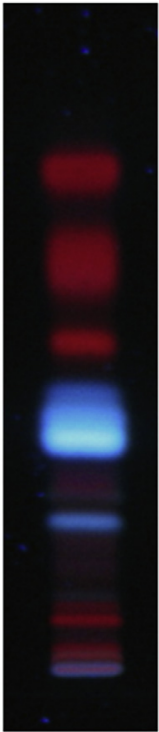

\section{A}

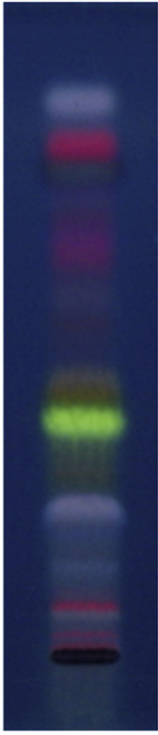

B

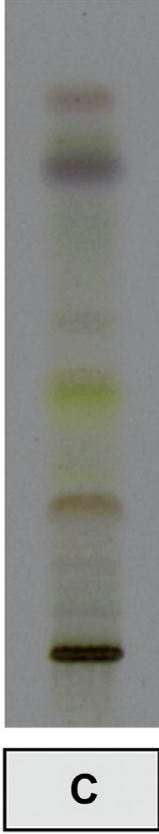

Fig. 3. Phytochemical fingerprint of $A$. conyzoides leaves on TLC plates; plate photo at, A: $366 \mathrm{~nm}$ without derivatization, B: $366 \mathrm{~nm}$ after derivatization and C: $550 \mathrm{~nm}$ after derivatization.

ectoparasites of humans and house animals. ${ }^{3}$ Essential oils/extracts from natural sources have exhibited significant pediculicidal activity in filter paper diffusion bioassay. ${ }^{7}$ Hence, in this research work filter paper diffusion bioassay was used to evaluate pediculicidal activity of HEACL.

The results of efficacy study are consigned in Table 4 and Table 5. Table 4 shows the record of \% mortality of head lice caused by application of HEACL, permethrin and Mediker. HEACL displayed concentration dependent activity among which concentration of $20 \%$ showed higher mortality and the results were at par with permethrin and Mediker treatment. This proves that the concentration plays an important role in the parasitical activity. ${ }^{7}$ HEACL (20\% concentration) and Mediker showed better pediculicidal effect than permethrin. Table 5 depicts the values of the lethal dose $\left(\mathrm{LD}_{50}\right)$ and their associated confidence intervals and regression equation with coefficient of determination at different time of exposures of HEACL against head lice. Decrease in the values of $\mathrm{LD}_{50}$ was observed as the time of exposure increased. The coefficient of determination $\left(r^{2}\right)$ for the regression line and regression equation was found much closure to 1.000 for the exposure time of 4560 min. As per the $\mathrm{LD}_{50}$ values of HEACL against head lice, treatment for the period of 45-60 min would be considered most efficacious. Pediculicidal activity of $A$. conyzoides leaves may be attributed to various phytochemical compounds along with eugenol (natural adulticidal and ovicidal agent ${ }^{2}$ ) present in the hydroalcoholic extract.

An effective pediculicide is required for the treatment of head lice infestation considering the increase in resistance to synthetic insecticides due to their repeated application. Though, a wide range of natural products such as olive, soy, sunflower, and corn oils has been routinely used in the management of pediculosis, they need to be applied in liberal quantities for more than $12 \mathrm{~h}$ in order to kill a significant number of lice and repeated treatments are recommended because of their low effectiveness. ${ }^{22}$ Thus, the results obtained from this research open a wide panorama for the use of HEACL as an effective alternative for controlling lice infestation.

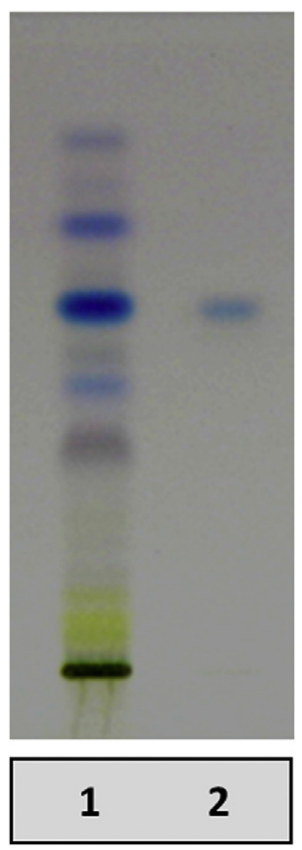

Fig. 4. HPTLC analysis of HEACL with eugenol at $550 \mathrm{~nm}$. Track details, 1: HEACL, 2 eugenol $(100 \mu \mathrm{g} / \mathrm{mL})$, plate was derivatized with $10 \%$ anisaldehyde sulphuric acid after development

Plant extracts have been reported for their safe and effective use and appearance of resistance pattern is minimal due to their different mode of action ${ }^{7}$ which greatly supports the safe use of HEACL as a potent anti-lice agent.

Table 2

The results of method validation parameters for eugenol using HPTLC technique.

\begin{tabular}{ll}
\hline Parameters & Results \\
\hline LOD and LOQ $(\mu \mathrm{g} / \mathrm{mL})$ & 20 and 40 \\
Linearity $(\mu \mathrm{g} / \mathrm{mL})$ & $40-180$ \\
Regression equation & $y=21.29 x-322.3$ \\
Mean coefficient of determination $\left(r^{2}\right)$ & 0.998 \\
System suitability (\% CV, $\boldsymbol{n}=\mathbf{5})$ & \\
$R_{f}$ & 1.76 \\
Area & 0.75 \\
Precision $(\% \mathbf{C V}, \boldsymbol{n}=\mathbf{3})$ & \\
Within-Batch & \\
Between-Batch & $0.65-0.91$ \\
Recovery (\%, $\boldsymbol{n}=\mathbf{7})$ & $1.31-1.57$ \\
Stability & 99.45 \\
Standard stock solution stability (For 10 days) & \\
Bench top stability (For 6.00 h) & Stable at $\left(4 \pm 1{ }^{\circ} \mathrm{C}\right)$ \\
Ruggedness & Stable at $\left(25 \pm 2{ }^{\circ} \mathrm{C}\right)$ \\
\hline
\end{tabular}

Table 3

Content of eugenol in A. conyzoides leaves (hydroalcoholic extract) collected from different geographical regions of Maharashtra.

\begin{tabular}{ll}
\hline Samples & Results in $\mathrm{mg} / \mathrm{g}($ mean $\pm \mathrm{SD}, n=3)$ \\
\hline Ambernath & $0.59 \pm 0.004$ \\
Bhiwandi & $0.69 \pm 0.006$ \\
Kalyan & $3.10 \pm 0.141$ \\
Matunga & $1.18 \pm 0.009$ \\
Murud & $0.58 \pm 0.004$ \\
Vashi & $0.81 \pm 0.005$ \\
\hline
\end{tabular}


Table 4

Percent mortality of head lice exposed to HEACL, permethrin and Mediker formulation.

\begin{tabular}{|c|c|c|c|c|c|c|}
\hline \multirow{3}{*}{\multicolumn{2}{|c|}{ Test samples }} & \multicolumn{5}{|c|}{ Average mortality (\%) } \\
\hline & & \multicolumn{5}{|c|}{ Exposure time (min) } \\
\hline & & 10 & 20 & 30 & 45 & 60 \\
\hline \multicolumn{2}{|c|}{ Negative control } & 3.3 & 3.3 & 6.7 & 13.3 & 13.3 \\
\hline \multicolumn{2}{|c|}{ Positive control } & 43.3 & 60.0 & 60.0 & 76.7 & 86.7 \\
\hline \multirow[t]{4}{*}{ HEACL } & $5 \%$ & 3.3 & 13.3 & 16.7 & 23.3 & 36.7 \\
\hline & $10 \%$ & 3.3 & 13.3 & 23.3 & 56.7 & 76.7 \\
\hline & $15 \%$ & 16.7 & 26.7 & 43.3 & 56.7 & 86.7 \\
\hline & $20 \%$ & 43.3 & 76.7 & 83.3 & 86.7 & 96.7 \\
\hline Medikeı & & 43.3 & 60.0 & 76.7 & 86.7 & 96.7 \\
\hline
\end{tabular}

\section{Table 5}

Values of the lethal dose $\left(L_{50}\right)$ and their associated confidence intervals, regression equation with coefficient of determination at different time of exposures of HEACL against head lice.

\begin{tabular}{|c|c|c|c|c|}
\hline $\begin{array}{l}\text { Exposure } \\
\text { time (min) }\end{array}$ & $\mathrm{LD}_{50}(\%)$ & $\begin{array}{l}\text { 95\% confidence } \\
\text { limits (upper } \\
\text { confidence limit - } \\
\text { lower confidence } \\
\text { limit) (\%) }\end{array}$ & Regression equation & $r^{2}$ \\
\hline 10 & 24.34 & $35.02-16.91$ & $y=3.20 x \pm 0.564$ & 0.711 \\
\hline 20 & 23.74 & $46.67-12.08$ & $y=2.63 x \pm 1.723$ & 0.623 \\
\hline 30 & 13.23 & $19.80-8.85$ & $y=2.89 x \pm 1.756$ & 0.768 \\
\hline 45 & 9.50 & $14.62-6.17$ & $y=2.70 x \pm 2.360$ & 0.879 \\
\hline 60 & 6.33 & $8.88-4.52$ & $y=3.45 x \pm 2.238$ & 0.980 \\
\hline
\end{tabular}

\section{Conclusion}

Findings of the present study indicate the potential of HEACL to be included in the formulations as pediculicidal agent. As in vitro efficacy tests of botanical extracts are only the first step of research and much work is needed before they could be used in a commercial product, efficacy of HEACL leaves must be proven for its delaying potential for nymph emergence or potential to kill the nymph. Other areas requiring attention are determination of pediculicidal mode of action and incorporation of the extract into formulations to improve its potency and stability as well as to reduce cost.

\section{Conflicts of interest}

All authors have none to declare.

\section{Acknowledgement}

Authors are thankful to Dr. Sasikumar Menon, Assistant Director, Institute of Advanced Training and Research in Interdisciplinary Sciences, Mumbai for giving helpful insights and suggestions in the statistical analysis of data. We would also like to thank Deepti Gurjar and Mayuresh Joshi for their technical assistance.

\section{References}

1. Jorge TCM, Lenartovicz V, Andrade MW, et al. Pediculicidal activity of hydroethanolic extracts of Ruta graveolens, Melia azedarach and Sambucus australis. Lat Am J Pharm. 2009;28:457-459.

2. Yang YC, Lee H, Lee SH, Clark JM, Ahn YJ. Ovicidal and adulticidal activities of Cinnamomum zeylanicum bark essential oil compounds and related compounds against Pediculus humanus capitis (Anoplura: Pediculicidae). Int J Parasitol. 2005;35:1595-1600.

3. Toloza AC, Zygadlo J, Biurrun F, Rotman A, Picollo M. Bioactivity of Argentinean essential oils against permethrin resistant head lice, Pediculus humanus capitis. J Insect Sci. 2010;10:185. Available online: insectscience.org/10.185.

4. Marimuthu S, Rahuman AA, Santhoshkumar T, et al. Lousicidal activity of synthesized silver nanoparticles using Lawsonia inermis leaf aqueous extract against Pediculus humanus capitis and Bovicola ovis. Parasitol Res. 2011;111:2023-2033.

5. Jadhav V, Kore A, Kadam VJ. In-vitro pediculicidal activity of Hedychium spicatum essential oil. Fitoterapia. 2007;78:470-473.

6. Priestley CM, Burgess IF, Williamson EM. Lethality of essential oil constituents towards the human louse, Pediculus humanus, and its eggs. Fitoterapia. 2006;77:303-309.

7. Samuel AJSJ, Radhamani S, Gopinath R, Kalusalingam A, Vimala AGKA Husain HA. In vitro screening of anti-lice activity of Pongamia pinnata leaves. Korean J Parasitol. 2009;47:377-380.

8. Nasrin F. Antioxidant and cytotoxic activities of Ageratum conyzoides stems. Int Curr Pharm J. 2013;2:33-37.

9. Mustafa MR, Mahmood AA, Sidik K, Noor SM. Evaluation of wound healing potential of Ageratum conyzoides leaf extract in combination with honey in rats as animal model. Int J Mol Med Adv Sci. 2005;1:406-410.

10. Ukwe VC, Epueke EA, Ekwunife OI, Okoye TC, Akudor GC, Ubaka CM. Antimalarial activity of aqueous extract and fractions of leaves of Ageratum conyzoides in mice infected with Plasmodium berghei. Int J Pharm Sci. 2010;2:33-38.

11. Adebayo AH, Tan NH, Akindahunsi AA, Zeng GZ, Zhang YM. Anticancer and antiradical scavenging activity of Ageratum conyzoides L. (Asteraceae). Pharmacog Mag. 2010;6:62-66.

12. Nyunai N, Manguelle-Dicoum A, Njifutie N, Abdennebi EH, Gerard C. Antihyperglycaemic effect of Ageratum conyzoides L. fractions in normoglycemic and diabetic male wistar rats. Int J Biomed Pharm Sci. 2010;4:38-42.

13. Mahmood AA, Sadik K, Salmah I, Suzaiur KAR, Philip K. Antiulcerogenic activity of Ageratum conyzoides leaf extract against ethanol induced gastric ulcer in rats as animal model. Int J Mol Med Adv Sci. 2005;1:402-405.

14. Kamboj A, Saluja AK. Ageratum conyzoides L.: a review on its phytochemical and pharmacological profile. Int J Green Pharm. 2008;2:59-68.

15. Okunade AL. Ageratum conyzoides L. (Asteraceae). Fitoterapia. 2002;73:1-16.

16. Government of India, Ministry of Health and Family Welfare. The Indian Pharmacopoeia. 6th ed. vol. I. Ghaziabad: The Indian Pharmacopoeia Commission; 2010:201.

17. Harborne JB. Phytochemical Methods - A Guide to Modern Techniques of Plant Analysis. 3rd ed. Delhi: Springer Private Ltd.; 2007:20-44.

18. Organization of Economic Co-operation and Development. Guidelines for Testing of Chemicals. No. 404. Acute Dermal Irritation/Corrosion, Paris. 2004.

19. Draize JH, Woodard G, Calvery HO. Methods for the study of irritation and toxicity of substances applied topically to the skin and mucous membranes. J Pharmacol Exp Ther. 1944:82:77.

20. Shailajan S, Menon S, Pednekar S, Singh A. Wound healing efficacy of Jatyadi Taila: in vivo evaluation in rat using excision wound model. J Ethnopharmacol. 2011;138:99-104.

21. Parasuraman S. Toxicological screening. J Pharmacol Pharmacother. 2011:2:74-79.

22. Carpinella MC, Miranda M, Walter RA, Ferrayol CG, Almeida FL, Palacios SM. In vitro pediculicidal and ovicidal activity of an extract and oil from fruits of Melia azedarach L. I Am Acad Dermatol. 2007:56:250-256.

23. Picollo MI, Vassena CV, Mougabure Cueto GA, Vernetti M, Zerba EN. Resistance to insecticides and effect of synergists on permethrin toxicity in Pediculus capitis (Anoplura: Pediculidae) from Buenos Aires. J Med Entomol. 2000;37:721-725.

24. Ming LC. Ageratum conyzoides: a tropical source of medicinal and agricultural products. In: Janick J, ed. Reprinted from: Perspectives on New Crops and New Uses. Alexandria: ASHS Press; 1999.

25. Shailajan S, Sayed N, Tiwari B. Impact of regional variation on lupeol content in Carissa carandas Linn. fruits: evaluation using validated high performance thin layer chromatography. J Adv Sci Res. 2013;4:21-24. 